\title{
REKONSTRUKSI SOSIAL EKONOMI (STUDI BUMDES SEBAGAI PEMBERDAYAAN MASYARAKAT NELAYAN DESA SANGIANG KABUPATEN BIMA)
}

\author{
Irdansyah $^{1}$ Eliza Meiyani ${ }^{2}$ \\ ${ }^{1}$ Pendidikan Sosiologi, Universitas Muhammadiyah Makassar \\ Email: irdansyah@gmail.com \\ ${ }^{2}$ Pendidikan Sosiologi, Universitas Muhammadiyah Makassar \\ Email: elizameiyani@unismuh.ac.id
}

\begin{abstract}
Abstrack. This study aims to determine the efforts of Bumdes among the community of the Sangiang Village Fishermen Community, Bima Regency, to find out the Socio-Economic Reconstruction in the Empowerment of the Sangiang Village Fishing Community of Bima Regency. This type of research is a qualitative study that is intended to discuss more about community empowerment through community service and the economic conditions of fishing communities. The informants were determined by purposive sampling based on the characteristics of the informants that had been determined namely the management of the BUMDes, the village government, and the sangiang village fishermen community. Data collection techniques are observation, documentation, and in-depth interviews. Data analysis through various stages, namely data reduction, data presentation, and conclusions, while the data validity techniques using triangulation of sources, techniques and time.

The research results found in this study from the aspects of Utilization: Bumdes In the utilization of BUMDES Enterprises in fishing communities in Sangiang Village have not produced results and fishermen conservation and have never received or benefited from BUMDES and also business unit units created by BUMDES Sangiang BUMDES management failed to take advantage of existing resources. While from the aspect of Socio-Economic Reconstruction: Reconstruction which is built or released from the beginning, which is built below contains primary values that must remain in rebuilding activities in accordance with the original situation which must be made so that it can be changed according to economic and social needs. fishing community.
\end{abstract}

Keywords: Socio-Economic Reconstruction, Bumdes and Empowering Fishing Communities

Abstrak. Penelitian ini bertujuan untuk mengetahui usaha Bumdes dikalangan masyarakat Masyarakat Nelayan Desa Sangiang Kabupaten Bima,Untuk mengetahui Rekonstruksi Sosial Ekonomi dalam Pemberdayaan Masyarakat Nelayan Desa Sangiang Kabupaten Bima. Jenis penelitian yang dilakukan adalah penelitian kualitatif yang bertujuan untuk memahami lebih dalam tentang pemberdayaan masyarakat lewat bumdes dan kondisi perekonomian masyarakat nelayan. Informan ditentukan secara purposive sampling berdasarkan karakteristik informan yang telah ditetapkan yaitu pengurus BUMDes, pemerintah desa, serta masyarkat nelayan desa sangiang. Teknik pengumpulan data yaitu observasi, dokumentasi, dan wawancara mendalam. Teknik analisis data melalui berbagai tahapan yaitu reduksi data, panyajian data, dan penarikan kesimpulan, sedangkan teknik keabsahan data menggunakan triangulasi sumber, teknik dan waktu.

Hasil penelitian yang ditemukan dalam penelitian ini dari aspek Pemanfaatan : Bumdes Dalam pemanfaatan Usaha BUMDES pada masyarakat nelayan Di Desa Sangiang belum membuahkan hasil dan menyentuh nelayan dan belum pernah mendapatkan atau merasakan manfaat dari BUMDES itu sendiri bahkan unit-unit usaha yang dibuat oleh pengurus bumdes BUMDES Sangiang telah gagal dalam memanfaatkan 
sumber daya yang ada. Sementara dari aspek Rekonstruksi Sosial Ekonomi : Rekonstruksi yang berarti membangun atau pengembalian kembali sesuatu berdasarkan kejadian semula, dimana dalam rekonstruksi tersebut terkandung nilai-nilai primer yang harus tetap ada dalam aktifitas membangun kembali sesuatu sesuai dengan kondisi semula harus dilakukan agar kemudian terjadi perubahan dalam aspek ekonomi maupun social masyarakat nelayan.

Kata Kunci : Rekonstruksi Sosial Ekonomi, Bumdes dan Pemberdayaan Masyarakat Nelayan

\section{PENDAHULUAN}

Pembangunan pada hakekatnya bertujuan membangun kemandirian, termasuk pembangunan pedesaan. Salah satu misi pemerintah adalah membangun daerah pedesaan yang dapat dicapai melalui pemberdayaan masyarakat untuk meningkatkan produktivitas dan keanekaragaman usaha pedesaan, ketersediaan sarana dan fasilitas untuk mendukung ekonomi pedesaan, membangun dan memperkuat institusi yang mendukung rantai produksi dan pemasaran, serta mengoptimalkan sumberdaya sebagai dasar pertumbuhan ekonomi pedesaan. Tujuannya, adalah untuk memberi peluang bagi kemampuan daerah dan pedesaan sebagai tulang punggung ekonomi regional dan nasional.

Kemajuan ekonomi nasional hanya akan tercapai jika terdapat iklim perekonomian yang baik di tingkat Provinsi. Kemajuan ekonomi di tingkat Provinsi akan tercapai jika kabupaten memiliki kegiatan ekonomi yang baik. Kemajuan ekonomi sebuah Kabupaten dapat tercapai karena adanya sumbangsih dari ekonomi pedesaan yang kuat yang berimbas pada kesejahteraan masyarakat luas. Hal ini akan menjamin penyelenggaraan pemerintahan yang baik untuk diterapkan di semua tingkat pembangunan dan keputusan berdasarkan kebutuhan nyata dari masyarakat. Pembangunan pedesaan merupakan salah satu cara dalam upaya mengentaskan kemiskinan di Indonesia.

Berdasarkan asumsi itulah maka sudah seharusnya eksistensi desa mendapatkan perhatian yang serius dari pemerintah pusat dengan lahirnya kebijakan-kebijakan terkait dengan pemberdayaan ekonomi yang dilakukan dengan cara menghimpun dan melembagakan kegiatan ekonomi masyarakat. Oleh karena itu pemerintah menerapkan pendekatan baru yang diharapkan mampu menstimulus dan menggerakkan roda perekonomian di pedesaan adalah melalui pendirian kelembagaan ekonomi yang dikelola sepenuhnya oleh masyarakat desa yaitu Badan Usaha Milik Desa (BUMDes) sebagai salah satu program andalan dalam meningkatkan kemandirian perekonomian desa.

Keberadaan BUMDes desa Sangiang diharapkan dapat mendukung munculnya kembali demokrasi sosial di desa melalui peningkatan kapasitas masyarakat desa tentang pengelolaan BUMDes secara berkelanjutan, dan partisipasi masyarakat desa terhadap BUMDes juga tidak lagi berkurang. Di sisi lain, pemerintah desa juga mampu berpola kreatif dan inovatif dalam mendominasi kegiatan ekonomi desa melalui kepemilikan BUMDes, sehingga dapat membangun perekonomian daerah yang dibutuhkan untuk menciptakan lapangan pekerjaan baru, menghasilkan barang dan jasa substitusi daerah, meningkatkan perdagangan antar-pemerintah daerah dan memberikan layanan yang optimal bagi konsumen.

\section{TINJAUAN PUSTAKA}

\section{a. Perspektif Teori Fakta Sosial}

Fakta sosial dinyatakan sebagai barang sesuatu (thing) yang berbeda dengan ide. Barang sesuatu menjadi objek penyelidikin seluruh ilmu pengetahuan. la tidak dapat dipahami melalui kegiatan mental murni (spekulatif). Tetatapi untuk memahamaminya diperlukan penyusunan data rilil di luar pemikiran manusia. Fakta sosial harus diteliti di dunia nyata sebagaimana orang mencari barang sesuatu yang lainnya. Pokok persoalan yang harus menjadi pusat perhatian penyelidikan 
menurut sosiologi menurut paradigma ini adalaha: fakta-fakta sosial. Secara garis besarnya fakta sosial terdiri atas dua tipe. Masing- masing adalah struktur sosial, dan pranata sosial. Sifat dasar serta antar hubungan dari fakta sosial inilah yang menjadi sasaran penelitian sosiologi menurut paradigma fakta sosial.

\section{b. Perspektif Teori Perubahan Sosial}

Semua orang bersepakat bahwa kehidupan sosial tidaklah statis, melainkan selalu berubahubah secara dinamis. Tetapi tidak semua orang mempunyai kesepakatan sama dalam mengartikan perubahan sosial. Malah konsep perubahan sosial sempit diberi makna intuitif dan sebagai suatu mitos belaka. Dimensi perubahn sosial yaitu struktural, kultural, dan interaksional. Dimensi struktural menampakkan diri pada perubahan-perubahan dalam status dan peran. Perubahan status dapat didefinisikan dari ada tidaknya perubahan pada peran, kekuasaan, ototritas, fungsi, integritas, hubungan antar status, arah kominkasi, dan seterusnya. Sementara itu, perubahan dalam dimensi dalam kultural bias di artikan dan diperhatikan ada tidaknya perubahan dalam budaya material (teknologi) dan non material (ide, nilai, peraturan, norma, kaidah sosial, yang menjadi collective consciousness di antara warga.

\section{c. Teori Struktural Fungsional}

Teori struktural fungsional melihat masyarakat sebagai sebuah keseluruhan sistem yang bekerja untuk menciptakan tatanan dan stabilitas sosial. Teori ini sering disebut juga perspektif fungsionalisme, dicetuskan oleh Emile Durkheim. Durkheim banyak mengkaji tentang tatanan sosial dan bagaimana masyarakat dapat hidup harmonis. Fungsionalisme fokus pada struktur sosial yang levelnya makro. Beberapa tokoh sosiologi yang terpengaruh oleh teori fungsionalisme Durkheim diantaranya, Talcott Parsons dan Robert K. Merton.

\section{d. Modal Sosial Sebagai Konsep Atau Teori Social}

Sudah banyak dikaji para ahli dan dijadikan dasar indicator dalam mengkaji suatu proses pembangunan yang berfokus pada kinerja kelompok.Menurut Shahra (2003) pertama kali pengertian modal sosial digulirkan oleh Lyda Judson Hanifan (1916) yang diartikan sebagai kiasan bukan dalam arti material, yaitu aset atau modal nyata yang penting dalam hidup masyarakat, termasuk kemauan baik, rasa bersahabat, saling simpati, serta hubungan sosial dan kerjasama yang serta antara individu dan keluarga yang membentuk suatu kelompok sosial. Selanjutnya Pierre Bourdieu (1986) menjelaskan modal sosial merupakan aspek sosial dan budaya yang memiliki nilai ekonomi dan dapat dilembagakan, yaitu keseluruhan sumber daya baik yang aktual maupun potensial yang terkait dengan kepemilikan jaringan hubungan kelembagaan yang tetap dengan didasarkan pada saling kenal dan saling mengakui. Kemudian Colemann (1999) mengartikan modal sosial adalah kewajiban dan harapan, saluran-saluran informasi dan norma-norma sosial.

\section{METODE PENELITIAN}

Jenis penelitian yang digunakan peneliti adalah penelitian deskriptif, yaitu penelitian sosial yang dianalisis secara kualitatif, yang menurut Miles dan Huberman (2009: 15) merupakan yang menghasilkan data yang muncul berwujud kata-kata bukan angka, data itu mungkin telah dikumpulkan dengan aneka macam cara (observasi, wawancara, intisari dokumen, pita rekaman), dan biasanya diproses kira-kira sebelum siap digunakan (melalui pencatatan, pengetikan, penyuntingan atau alih-tulis), tetapi analisis kualitatif tetap menggunakan kata-kata yang biasanya disusun ke dalam teks yang diperluas. Dengan kata lain penelitian ini sangat bergantung pada informasi yang didapat saat melakukan penelitian di lapangan. Hal-hal yang menjadi Sasaran penelitian dalam penelitian ini adalah masyarakat Nelayan Desa Sangiang, Kabupaten Bima. Dalam penelitian teknik pengambilan informan yang digunakan peneliti adalah purposive sampling yaitu dengan memilih secara langsung informan berdasarkan kriteria yang telah ditentukan peneliti. Jumlah informan dalam penelitian 6 orang. Adapun yang menjadi informan kunci adalah : Kepala Desa dan Sekertaris Desa dan yang menjadi informan Ahli adalah : Ketua BUMDes, dan Bendahara BUMDes. Adapun teknik pengumpulan data yang dilakukan dalam penelitian ini adalah: observasi, 
dokumentasi, partisipatif,. Untuk memperoleh hasil penelitian yang lengkap, tepat dan benar, maka diperlukan metode yang valid dalam menganalisa data.

\section{HASIL DAN PEMBAHASAN}

Setelah melakukan observasi, dokumentasi, partisipatif,dan angket di lapangan maka akan disajikan data-data yang diperoleh dari penelitian. Untuk lebih jelasnya dapat dilihat sebagai berikut:

\section{Pemanfaatan Usaha Bumdes Dikalangan Masyarakat Nelayan Desa Sangiang}

Keberadaan BUMDES di desa Sangiang diharapkan dapat mendukung munculnya kembali demokrasi sosial di desa melalui pemanfaatan dan pengelolaan BUMDES untuk nelayan. Dalam bagian ini, peneliti memfokuskan kepada bagaimana pemanfaatan usaha BUMDES pada masyarakat nelayan desa sangiang. Dalam pemanfaatan usaha bumdes pada masyarakat nelayan di desa sangiang belum membuahkan hasil dan menyentuh nelayan dan belum pernah mendapatkan atau merasakan manfaat dari bumdes itu sendiri bahkan unit-unit usaha yang dibuat oleh pengurus BUMDes Sangiang telah gagal dalam memanfaatkan sumber daya yang ada. Nelayan tidak pernah diberdayakan untuk peningkatan ekonomi desa. Buktinya sederhana, tidak ada satupun program untuk mereka. Bahkan menurut masyarakat nelayan di desa sangiang mereka mengatakan bahwa selama ini sejak berdirinya bumdes belum pernah ada sosialisasi pengurus bumdes tentang bumdes dan manfaat bumdes untuk nelayan bahkan usaha dari bumdes bagi nelayan tidak ada.

\section{Pemberdayaan Masyarakat Nelayan Desa Sangiang}

Program BUMDES sesungguhnya memiliki peran yang strategis dalam pembangunan dan pemberdayaan masyarakat desa. Dengan mengusung semangat gotong royong program BUMDES tidak hanya memberikan keuntungan berupa pembangunan dalam aspek fisik tetapi juga keuntungan dalam aspek sosial. Di dalam pembangunan desa terdapat dua aspek yaitu pembangunan desa dalam aspek fisik dan dalam aspek pemberdayaan masyarakat. Sedangkan pemberdayaan masyarakat merupakan upaya untuk meningkatkan kemampuan dan potensi yang dimiliki oleh masyarakat sehingga mewujudkan jati diri, harkat dan martabat masyarakat secara maksimal dan digunakan untuk mempertahankan dan mengembangkan diri secara mandiri baik secara ekonomi, social.

Pendekatan pemberdayaan masyarakat dalam pembangunan mengandung arti bahwa manusia ditempatkan pada posisi pelaku dan penerima manfaat dari proses mencari solusi dan meraih hasil pembangunan.

Upaya-upaya pemberdayaan masyarakat seharusnya mampu berperan meningkatkan kualitas sumberdaya manusia (SDM) terutama dalam membentuk dan merubah perilaku masyarakat untuk mencapai taraf hidup yang lebih berkualitas. Pemberdayaan masyarakat tidak lain adalah memberikan motivasi dan dorongan kepada masyarakat agar mampu menggali potensi dirinya dan berani bertindak memperbaiki kualitas hidupnya, melalui cara antara lain dengan pendidikan untuk penyadaran dan pemampuan diri mereka.

Namun fakta sosial yang ada di Desa sangiang yaitu BUMDES belum dapat menjalankan fungsinya secara maksimal sebagaimana mestinya dalam pemberdayaan masyarakat nelayan desa sangiang.

Dengan demikian masyarakat nelayan desa Sangiang sangat berharap ditinjau kembali Kebijakan sosial ekonomi (pendidikan, kesehatan, ekonomi, infrastruktur dan kelembagaan) dalam pengembangan dan pemberdayaan masyarakat nelayan yang "tertinggal" perlu direkayasa ulang terutama yang berkaitan dengan bidang atau unit usaha yang dibentuk oleh pengurus bumdes Disisi lain, rendahnya sumber daya manusia (SDM) dan peralatan yang digunakan nelayan berpengaruh pada penangkapan ikan.

Masalah tersebut telah menimbulkan dampak negatif yang luas terhadap kehidupan masyarakat nelayan. Sehingga kemudian perlu kiranya Rekonstruki yang berarti membangun atau 
pengembalian kembali sesuatu berdasarkan kejadian semula, dimana dalam rekonstruksi tersebut terkandung nilai-nilai primer yang harus tetap ada dalam aktifitas membangun kembali sesuatu sesuai dengan kondisi semula harus dilakukan agar kemudian terjadi perubahan dalam aspek ekonomi maupun social masyarakat nelayan. lewat rekonstruksi bumdes sebagai lembaga usaha milik desa yang fungsinya memberdayakan masyarakat desa dan mengelola segala asset, potensi desa sesuai dengan kebutuhan serta kondisis masyarakat desa sangiang yang mayoritas sebagai nelayan. Masyarakat sangat berharap pemerintah desa Sangiang melalui BUMDES mampu mengelolah sumber daya tersebut, namun tidak pernah ada kata untuk itu, alias tidak ada program atau unit usaha yang dibentuk oleh BUMDES untuk mengelolah sumber daya itu.

\section{KESIMPULAN}

Berdasarkan hasil penelitian yang dilakukan di Desa Sangiang Sangiang, maka dapat ditarik kesimpulan tentang "Rekonstruksi Sosial Ekonomi (Studi BUMDes Sebagai Pemberdayaan Masyarakat Nelayan Desa Sangiang Kabupaten Bima)" adalah sebagai berikut :

1. Bumdes Dalam pemanfaatan Usaha BUMDES pada masyarakat nelayan Di Desa Sangiang belum membuahkan hasil dan menyentuh nelayan dan belum pernah mendapatkan atau merasakan manfaat dari BUMDES itu sendiri bahkan unit-unit usaha yang dibuat oleh pengurus bumdes BUMDES Sangiang telah gagal dalam memanfaatkan sumber daya yang ada. Nelayan tidak pernah diberdayakan untuk peningkatan ekonomi desa. Buktinya sederhana, tidak ada satupun program untuk mereka. Bahkan menurut masyarakat nelayan di Desa Sangiang mereka mengatakan bahwa selama ini sejak berdirinya BUMDES belum pernah ada sosialisasi pengurus BUMDES tentang bumdes dan manfaat BUMDES untuk nelayan bahkan usaha dari bumdes bagi nelayan tidak ada.

2. Rekonstruksi yang berarti membangun atau pengembalian kembali sesuatu berdasarkan kejadian semula, dimana dalam rekonstruksi tersebut terkandung nilai-nilai primer yang harus tetap ada dalam aktifitas membangun kembali sesuatu sesuai dengan kondisi semula harus dilakukan agar kemudian terjadi perubahan dalam aspek ekonomi maupun social masyarakat nelayan.diatas dapat disimpulkan bahwa bumdes dalam pelaksanaakan fungsi dan tugasnya sebagai lembaga pemberdayaan untuk masyarakat desa dengan berbagai program dan usaha untuk masyarakat nelayan desa sangiang belum menyentuh dan memberikan manfaatnya dalam pemberdayaan masyarakat nelayan yang kemudian diharapkan memberikan peningkatan SDM nelayan dan meningkatkan perekonomian mereka khususnya desa sangiang dan BUMdes sebagai badan usaha milik dengan yang di berikan modal oleh desa untuk pemberdayaan masyarakat desa lebihlebih para nelayan. Hal ini didapatkan melalui hasil wawancara dari beberapa informan yang telah memberikan informasi mengenai pemanfaatan BUMdes untum masyarakat Nelayan desa sangiang dan sebagai lembaga pemberdayaan masyarakat Desa sangiang.

\section{DAFTAR PUSTAKA}

Adi, Isbandi Rukminto. 2013. Intervensi Komunitas dan Pengembangan Masyarakat Sebagai Upaya Pemberdayaan Masyarakat. Jakrta: Rajawali Pers.

Creswell, John W. 2010. Reserch Design Pendekatan Kualitatif, Kuantitatif, Dan Mixed. Yogyakarta: Pustaka Pelajar.

Damsar. 2010. Pengantar Sosiologi Politik. Jakarta: Kencana.

Desyandri. 2013. Aliran Filsafat Rekonstruksi Sosial/Budaya, (online), (https://desyandri.wordpress.com/2013/12/27/aliran-filsafat-rekonstruksi-sosialbudaya/, diakses 24 Januari 2018).

Fink, Hans. Filsafat Sosial Dari Feodalisme Hingga Pasar Bebas. Yogyakarta: Pustaka Pelajar. 
Giddnes, Anthony. 2009. Problematika Utama Dalam Teori Sosial Aksi, Struktur, Dan Kontradiksi Dalam Analisis Sosial. Yogyakarta: Pustaka Pelajar.

Giddnes, Anthony. 2016. Teori Strukturasi Dasar-Dasar Pembentukan Struktur Soial Masyarakat. Yogyakarta: Pustaka Pelajar.

Jahar, Asep Saipudin dkk. 2013. Sosiologi Sebuah Pengantar Tinjauan Pemikiran Sosiologi Islam. Jakarta: Laboratorim Sosiologi Agama.

Rahim, Manat dkk. 2014. Model Pemberdayaan Masyarakat Di Wilayah Pesisir Dalam Menanggulangi Kemiskinan Di Kabupaten Buton, Sulawesi Tenggara. Journal The WINNERS. 15 (1): 23-

Ritzer, George. 2014. Sosiologi Ilmu Pengetahuan Berparadigma Ganda. Jakarta: Rajawali Pers.

Sujarwa. 2014. Ilmu Sosial Dan Budaya Dasar Manusia Dan Fenomena Sosial Budaya. Yogyakarta: Pustaka Pelajar.

Samadara, Salfasina dkk. 2016. Pemberdayaan Ekonomi Masyarakat Berbasis Kemitraan (Studi Kasus Nelayan Desa Sulamu Kabupaten Kupang NTT). Jurnal Bisnis dan Manajemen Islam. 4 (1).

Sutoro Eko, 2002, Pemberdayaan Masyarakat Desa, Materi Diklat Pemberdayaan Masyarakat Desa, Badan Diklat Provinsi Kaltim, Samarinda.

Turner, Bryan S. 2012. Teori Sosial Dari Klasik Sampai Postmodern. Yogyakarta: Pustaka Pelajar.

Usman, Sonyoto. 2010. Pembangunan dan Pemberdayaan Masyarakat. Yogyakarta: Pustaka Pelajar.

Widjaja, Haw. 2014. Otonomi Desa Merupakan otonomi yang Asli, Bulat dan Utuh. Jakarta: Rajawali Pers.

Yusuf, Muh. Jufri. 2013. Studi Tentang Pemberdayaan Masyarakat Pesisir Di Kabupaten Nunukan ( Studi Kasus Di Kelurahan Nunukan Selatan Kecamatan Nunukan Selatan). Journal Ilmu Pemerintahan. 1 (4).

Ratna Azis Prasetyo Airlangga University : Peranan Bumdes Dalam Pembangunan Dan Pemberdayaan Masyarakat Di Desa Pejambon Kecamatan Sumberrejo Kabupaten Bojonegoro. Jurnal Dialektika Volume XI No.1 Maret 2016

Kadek Darwita dan Dewa Nyoman Redana: Peranan Badan Usaha Milik Desa (BUMDES) Dalam Pemberdayaan Masyarakat Dan Penanggulangan Pengangguran Di Desa Tejakula Kecamatan Tejakula Kabupaten Buleleng 2018. Locus Majalah IImiah FISIP Vol 9 No. 1 Pebruari 2018 